\title{
FRACTURE RESISTANCE OF A NEWLY PROPOSED OCCLUSAL VENEER DESIGN USING TWO DIFFERENT CAD/CAM CERAMIC MATERIALS
}

\author{
Carl Hany Halim *
}

\begin{abstract}
Statement of the Problem: Management of severe occlusal erosive lesions constitutes a challenging therapeutic approach to the restorative dentist. Bonded occlusal veneers have been introduced as a conservative solution to traditional onlays or complete coverage crowns. Still, there is lack of information and conflict in the data concerning the mechanical performance of the occlusal veneer materials and designs.
\end{abstract}

Purpose: The purpose of this in vitro investigation was to evaluate and compare the fracture resistance and failure mode of a newly proposed occlusal veneer design constructed of zirconia reinforced lithium silicate and hybrid ceramic materials with the conventional design restored with the same tested materials.

Materials and Methods: Two maxillary first molars of a typodont were chosen to perform the master preparations; one for the conventional planar occlusal veneer design, and the second for the proposed modified design which consisted of occlusal veneer preparation with circumferential chamfer finish line and two shallow proximal slots. Ten elastomeric impressions were taken for each design using the putty and light polysiloxane addition silicone impression material. The twenty impressions were poured using type IV dental stone to produce twenty stone casts, ten for each design. Each group of stone casts was subdivided randomly into two equal subgroups according to the ceramic material to be tested; the zirconia reinforced lithium silicate "Celtra Duo" and the hybrid resin nano ceramic "Lava Ultimate". All the occlusal veneers were fabricated using the CAD/CAM Cerec InLab SW 4.2.5 System. The veneers were then checked on both the stone casts and the master preparation on the typodont for perfect seating, after the Celtra veneers were crystallized and glazed and the Lava veneers being subjected to finishing and polishing. The preparations were duplicated to obtain twenty epoxy casts over which the occlusal veneers were adhesively cemented using a standard bonding protocol. The samples were then subjected to thermal cycling program. All the samples were individually mounted on the Instron testing machine with a loadcell of $5 \mathrm{KN}$ and fracture test was done by compressive mode of load applied occlusally using a metallic rod with spherical tip (5.6 mm diameter) at cross-head speed of $1 \mathrm{~mm} / \mathrm{min}$. The load required to fracture was recorded in Newton and tabulated to be statistically analyzed. The fractured specimens were examined to detect the mode of failure.

* Associate Professor, Fixed Prosthodontics Dept. Faculty of Dentistry, Cairo University 
Results: Regardless of the ceramic type, the modified occlusal veneer design showed statistically significant higher fracture resistance mean value $(1106.0 \mathrm{~N})$ than conventional design $(957.6 \mathrm{~N})$ at $\mathrm{P} \leq 0.05$. Irrespective of the design, the Lava Ultimate revealed higher statistically significant fracture resistance mean value $(1114.1 \mathrm{~N})$ than Celtra $(949.5 \mathrm{~N})$ at $\mathrm{P} \leq 0.05$. The Celtra veneers showed higher fracture resistance mean value $(1016.9 \mathrm{~N})$ with the conventional design than the modified design $(882.2 \mathrm{~N})$, the difference was statistically significant at $\mathrm{P} \leq 0.05$. While the lava veneers presented higher statistically significant fracture resistance mean value with the modified design $(1329.9 \mathrm{~N})$ than the conventional design $(898.3 \mathrm{~N})$ at $\mathrm{P} \leq 0.05$. All the specimens exhibited cracks limited to the veneer material, except one revealed catastrophic failure.

\section{Conclusions:}

1. The modified occlusal veneer design offered promising results as far as fracture resistance is concerned particularly with the nano-hybrid ceramic which presented the highest statistically significant fracture resistance mean values.

2. The conventional planar occlusal veneer design proved to be superior with zirconia lithium silicate ceramic (ZLS) as it presented highly significant fracture resistance mean values than with the modified design.

3. Both the conventional and modified occlusal veneer designs presented fracture resistance mean values with the two tested materials "Celtra and Lava Ultimate" that exceed the range of clinical acceptability.

4. Rating of the tested occlusal veneers according to their fracture resistance mean values is as follows: the highest for the Lava Ultimate with the modified design, followed by Celtra Duo with conventional design, then Lava Ultimate with conventional design and Celtra Duo with modified design.

5. It can be recommended that in cases with increased occlusal stresses, Lava Ultimate occlusal veneer with the modified design be the first choice, followed by the Celtra Duo with the conventional design as a second choice.

KEYWORDS: Occlusal veneer design, CAD/CAM, ceramic materials, fracture resistance.

\section{INTRODUCTION}

The growing interest in minimally invasive approach to restore teeth together with the great benefits achieved with the adhesive concept and the multiplicity of newly introduced ceramic materials have urged the restorative dentists to solve many of the esthetic, functional and biologic dental problems. Magne and Belser, ${ }^{1}$ reported that conservation of tooth structure is important for maintaining the equilibrium between biologic, mechanical, functional and esthetic parameters. Abrahamsen, ${ }^{2}$ stated that pathologic loss of coronal tooth structure like abrasion and/erosion of enamel and dentin might be attributed to a multitude of individual or combined etiologic factors related to dietary and oral habits. This disorder is habitually diagnosed at an advanced stage when a considerable loss of dental tissue has occurred (Lussi et al). ${ }^{3}$ This tooth structure loss affects the musculoskeletal harmony, occlusal stability, oral comfort, esthetics, and patients' satisfaction with their dentition (Turner and Missirlian, ${ }^{4}$ and Al-Omiri et al ${ }^{5}$ ). Restorative treatment of this severely worn dentition was traditionally performed using multiple full-coverage restorations, crown lengthening, and elective tooth devitalization. ${ }^{6}$ However, for the interest of limiting the amount of adjunctive procedures required for dental reconstruction, the trend toward conservatism in tooth preparation and restoration design is strongly re-emerging. ${ }^{7-9}$ 
The translational application of principles used in treatment with anterior porcelain laminate veneers led to the proposal for posterior "occlusal veneers", which are extra- coronal restorations requiring a simpler and more intuitive preparation driven by interocclusal clearance and anatomical consideration. ${ }^{10}$ Development of stronger materials such as lithium disilicate ceramics, hybrid ceramics and the CAD/CAM technology, ${ }^{11-15}$ together with the innovative adhesive bonding protocols such as immediate dentin sealing, ${ }^{16-20}$ have encouraged the introduction of bonded occlusal veneers as a conservative alternative to traditional onlays and complete coverage crowns for the treatment of severe erosion. ${ }^{10,15}$ Federlin et al ${ }^{21}$ and Manhart et al, ${ }^{22}$ advocated the choice of ceramics as an enamel replacement and relied mainly on their strength and thickness, together with the effective bonding to the underlying prepared tooth structure. ${ }^{23,24}$ Tsitrou et al, ${ }^{25}$ found that computerized restorative dentistry might be the best solution for uniting tooth structure conservation with simple convenient and affordable restoration. Johnson et al, ${ }^{26}$ reported that with CAD/CAM technology, such minimally invasive restorations could be machine-milled from various restorative materials for the re-establishment of posterior occlusal contours. Owing to the continuous innovations of monolithic glass ceramic, in order to optimize their strength properties, Zirconia lithium silicate (ZLS), which belongs to a new generation of CAD/CAM materials that combine the optimistic mechanical properties of zirconia with the glass ceramic translucency, was recently introduced. ${ }^{27,28}$ The ZLS ceramics have a dual microstructure consisting of a lithium metasilicate ( $\mathrm{Li} 2 \mathrm{SiO} 3)$ glass ceramic and reinforced with approximately $10 \%$ (by weight) of zirconium dioxide ( $\mathrm{ZrO} 2)$. Zirconia lithium silicate is provided in a soft and easily formable partially crystallized state, to ease the CAD/CAM manufacturing: it is later treated to attain a fully crystallized state with final color and appropriate properties. After the final crystallization process, a very fine grained microstructure is obtained ( $\mathrm{Li} 2 \mathrm{O}$ - $\mathrm{ZrO} 2$ - SiO2) ${ }^{29}$ The ZLS could be etched and cemented with adhesive systems unlike the zirconia restorations. ${ }^{30}$ New composite and ceramic hybrid materials have been recently introduced as well, which can be milled at relatively thin thicknesses to accommodate conservative tooth preparations. ${ }^{25}$ The resin nano-ceramic is neither a composite nor a pure ceramic, but a mixture of both. ${ }^{31}$ Little research has been done to investigate the mechanical performance of these recent materials when utilized as minimal thickness posterior occlusal veneers. ${ }^{15,32}$ Most of the related experiments have tested the fracture strength and fatigue resistance o both ceramic and non-ceramic materials as inlays, onlays, partial and complete coverage crowns. ${ }^{33-35}$ Johnson et al, ${ }^{26}$ in a recent study found that decreasing the thickness of occlusal veneers made with CAD/CAM composite (3M Paradigm MZ 100, 3M ESPE, St Paul, MN) or resin nano-ceramic (3M Lava Ultimate, 3M ESPE) to $0.3 \mathrm{~mm}$ did not affect the fracture strength.

However, reviewing the dental literature on this area of minimally invasive occlusal veneer restorations revealed that most of the investigators stressed on studying the mechanical performance of the veneers as a function of the different tested materials and different thicknesses rather than considering the design features of the preparation. Therefore, the aim of the present in vitro investigation was to evaluate and compare the fracture resistance and failure mode of a newly proposed occlusal veneer design constructed of zirconia reinforced lithium silicate (ZLS) and hybrid ceramic materials with the conventional design restored with the same tested materials.

The null hypothesis of the present research was that there would be no significant differences in the fracture resistance between the two designs or among the two different materials. 


\section{MATERIALS AND METHODS}

Two maxillary first molars of a Typodont model (NISSIN Dental Model, Kyoto Japan) were chosen to perform the master preparations; one for the conventional planar occlusal veneer design, and the second for the proposed modified design. A standard set of diamond rotary instruments (Mani DIA-BURS- TOCHIGI, JAPAN) suitable for different ceramic preparations was used to secure both the conventional and the proposed occlusal veneer preparations. For the conventional design preparation (Group I) tapered round end diamond stone was used to prepare the occlusal surface following occlusal anatomy and reducing it by 1.5 $\mathrm{mm}$ at the cusp tip and $1 \mathrm{~mm}$ at the fossa (Fig 1). Putty indices were used to check the uniformity and the amount of reduction. A digital caliper (Electronic Digital Caliper Micrometer Gauge, Tri Circle, Shanghai, China) was also used in assessment of preparation dimensions. Finishing and smoothening of the preparation were executed using tapered round end fine and extra fine grit diamond stones. The newly proposed occlusal veneer (Group II) was designed to have one mm circumferential finish line and two shallow proximal slots; two mm width and one and half mm depth. Preparation of the occlusal surface was carried out as in the conventional design (Group I), then tapered round end medium grit diamond stones were used to prepare the axial walls to one and half $\mathrm{mm}$ height to create the one $\mathrm{mm}$ circumferential chamfer finish line. The two proximal slots were prepared using tapered round end medium grit diamond stones having two $\mathrm{mm}$ tip diameter and $8^{\circ}$ taper. The taper of the stone was calculated using MAGAFOR Taper and Angle Calculation Computer Program. Finishing and smoothening of the preparation was carried out using tapered round end fine and extra fine grit diamond stones (Fig 2). Assessment of the accuracy of the preparation dimensions was performed with the putty index and the electronic digital caliper as described before. Elastomeric impression making of the two prepared occlusal veneer designs was carried out, ten impressions for each using the puttylight polyvinyl siloxane impression material (Elite HD + A Silicone, Zhermack- Badia Polesine-Italy), using sectional stainless steel perforated stock trays to limit and minimize any possible defects or errors and to optimize the impression accuracy (Fig 3 and 4). The twenty elastomeric impressions of the two experimental groups after being checked thoroughly for accuracy were then poured with Type IV dental stone (Fujirock EP; GC America Inc.) to produce twenty stone models, ten per each occlusal veneer design (Fig 5 a and b). Each group of stone models (groups I and II) was randomly subdivided into two equal subdivisions, five per each, according to the ceramic material to be tested; the Zirconia reinforced lithium silicate (ZLS) Celtra Duo (Dentsply, Sirona, Degudent, GmbH, Germany) and the hybrid composite ceramic Lava Ultimate (3M ESPE, St. Paul, MN) Table 1.

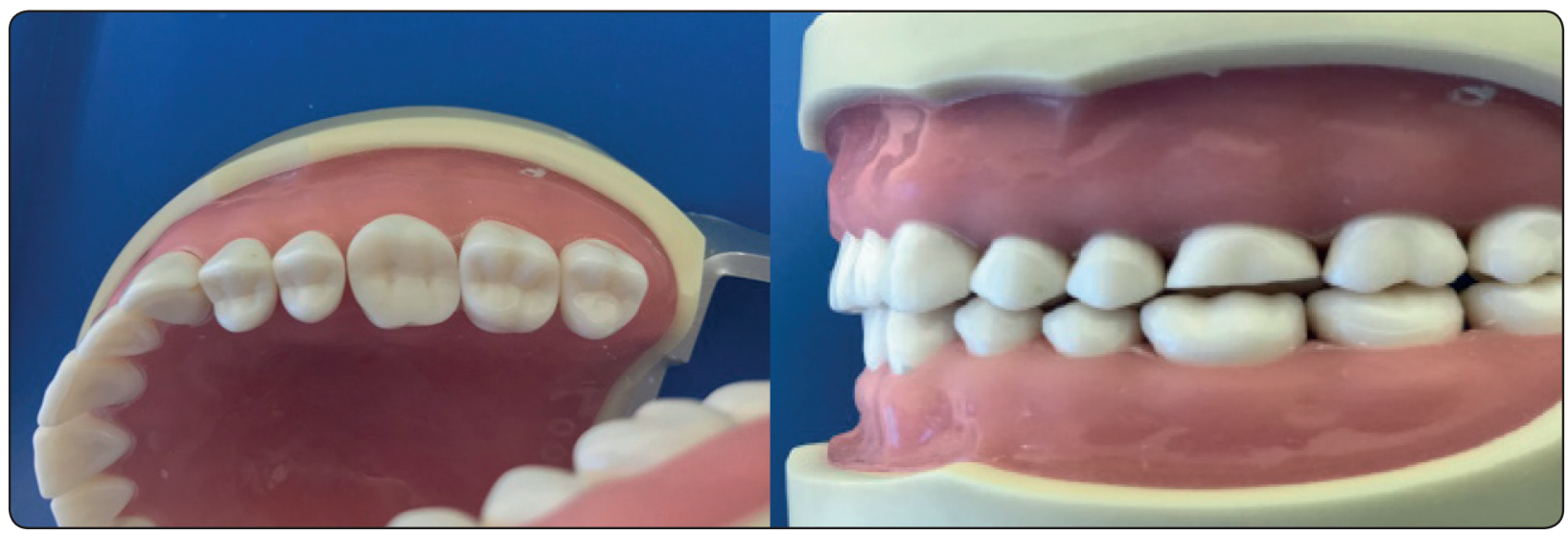

Fig. (1) Conventional Design preparation (Group 1) with $1.5 \mathrm{~mm}$ depth reduction at cusp tip and $1 \mathrm{~mm}$ at the fossa. 

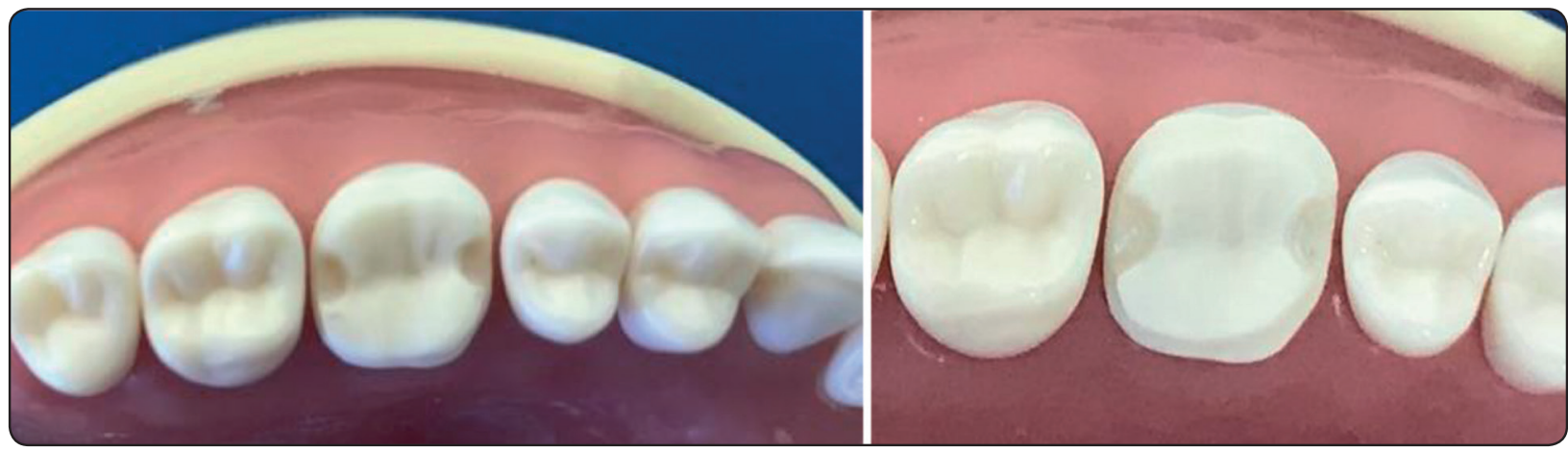

Fig. (2) The newly proposed occlusal veneer preparation design with $1 \mathrm{~mm}$ circumferential chamfer and 2 shallow proximal slots.

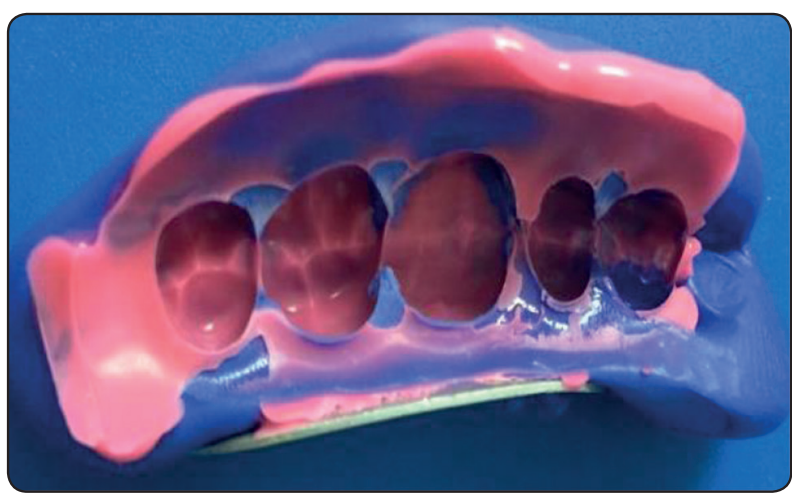

Fig. (3) Elastomeric impression of the conventional occlusal veneer design.

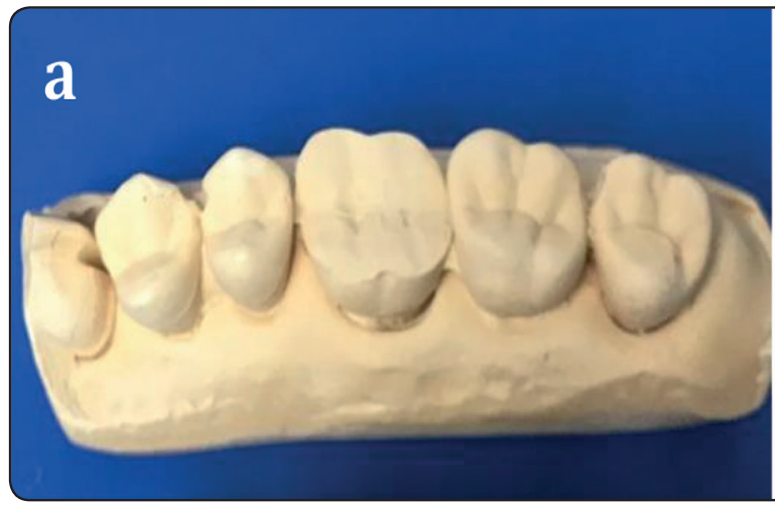

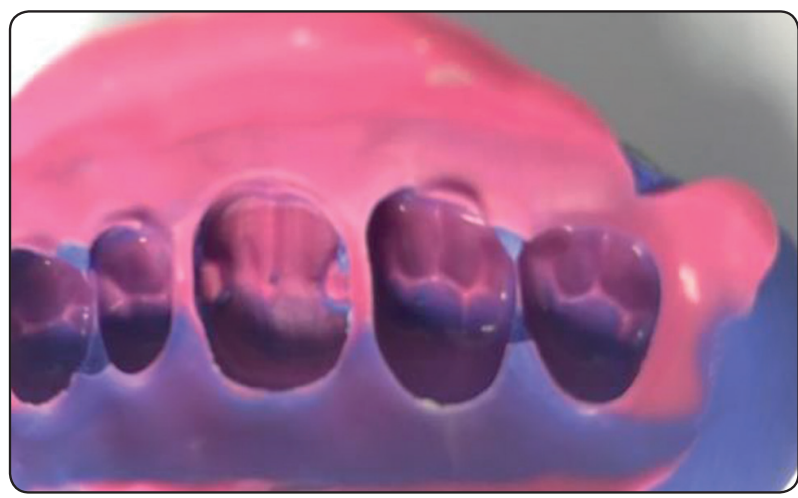

Fig 4: Elastomeric impression of the modified occlusal veneer design.

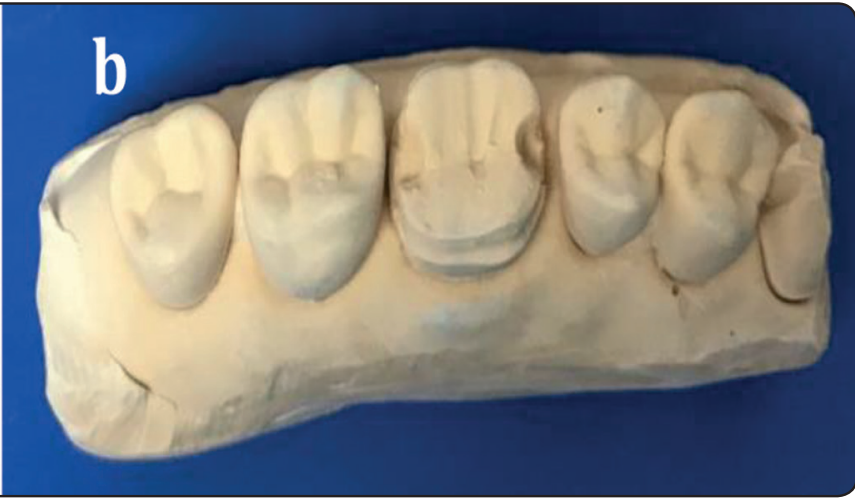

Fig 5: Stone model of the conventional occlusal veneer design on the maxillary first molar (a) and the modified design (b).

TABLE (1) Grouping of the experimental samples according to the occlusal veneer design and the tested ceramic material

\begin{tabular}{|c|c|c|c|}
\hline Groups & $\begin{array}{c}\text { Subgroup A } \\
\text { Celtra }\end{array}$ & $\begin{array}{c}\text { Subgroup B } \\
\text { Lava }\end{array}$ & Total \\
\hline Group I Conventional design & 5 & 5 & 10 \\
\hline Group II Modified design & 5 & 5 & 10 \\
\hline Total & 10 & 10 & 20 \\
\hline
\end{tabular}


Optical impressions of the two different occlusal veneer preparations on the stone models were captured using the Cerec inEos X5 (Sirona Dental Systems Gmbh) using multiple rapid fully automated exposures to create a 3D virtual model (Fig 6). Eight single scans were taken in rapid succession, the computer software (inLab 4.2.5) combined these eight scans until a single clear image was displayed on the screen, which was then stored on the computer. The insertion axis was then defined to determine the alignment of the $3 \mathrm{D}$ model in the virtual design, which is so important for the initial proposal and milling of the restoration. The die spacer was set at $30 \mu \mathrm{m}$ according to Nakamura et al, ${ }^{36}$ since ceramic restorations should display a passive fit. The design of the occlusal veneers was performed using the biogeneric feature of the cerec inLab software (Fig 7). The restoration parameters were fixed for all the restorations $(\mathrm{N}=20)$ of the two tested groups to have minimal occlusal thickness of one $\mathrm{mm}$ and minimal radial thickness of one $\mathrm{mm}$ (Fig 8). Slicing tool was used to split the model and restoration vertically and adjust the distance between central groove of the restoration and the occlusal surface at $1 \mathrm{~mm}$ and cusp height at $1.5 \mathrm{~mm}$ (Fig 8)

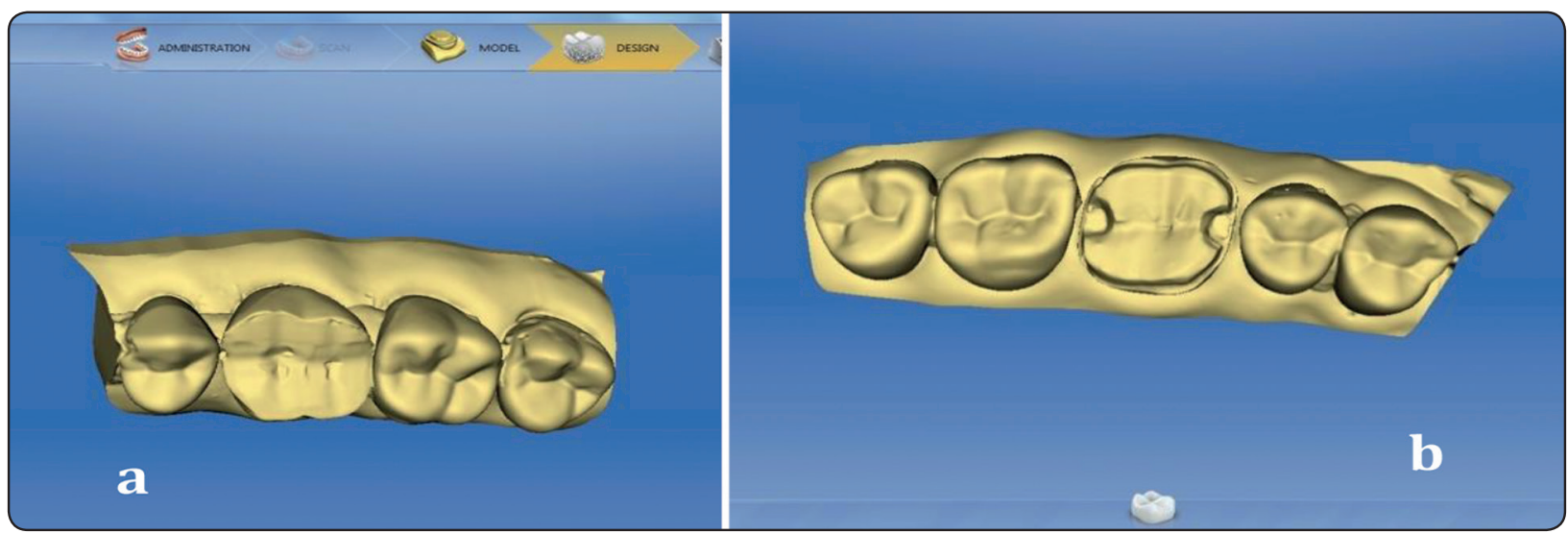

Fig. (6) 3D virtual model on the 4.2.5 inLab software obtained by inEOS showing the conventional occlusal veneer preparation design (a) and the modified design (b).

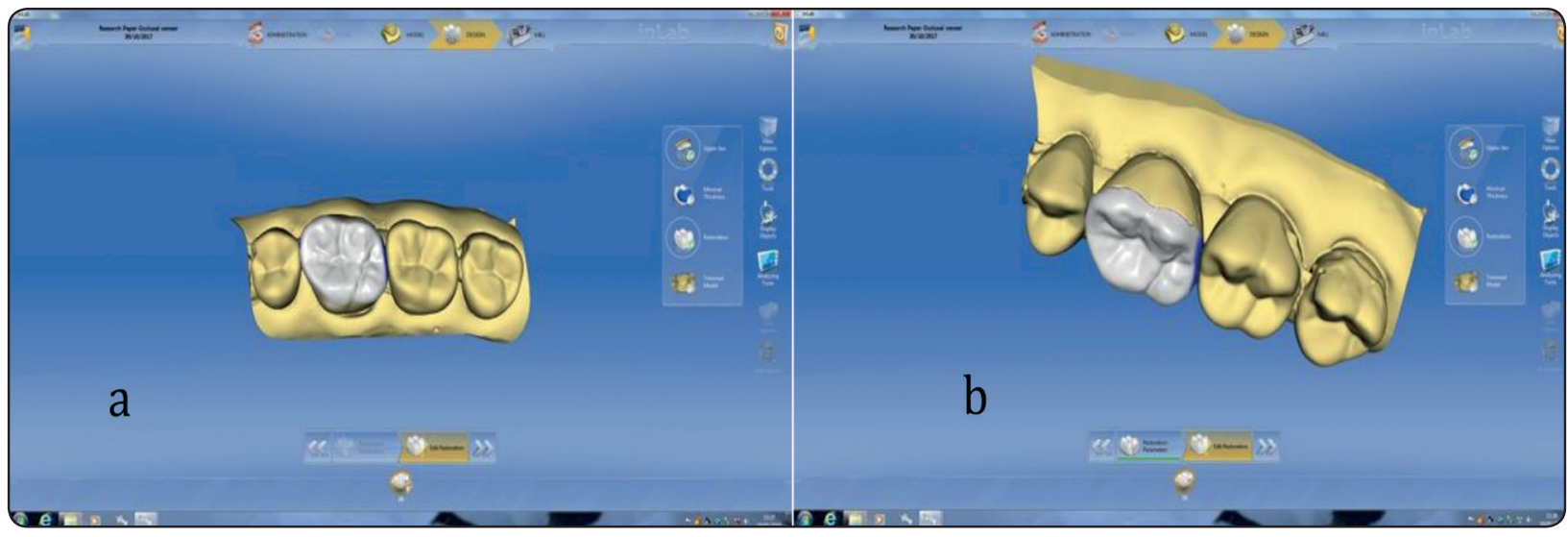

Fig. (7) Virtual 3D model with the proposed conventional occlusal veneer design (a) and the modified design (b). 


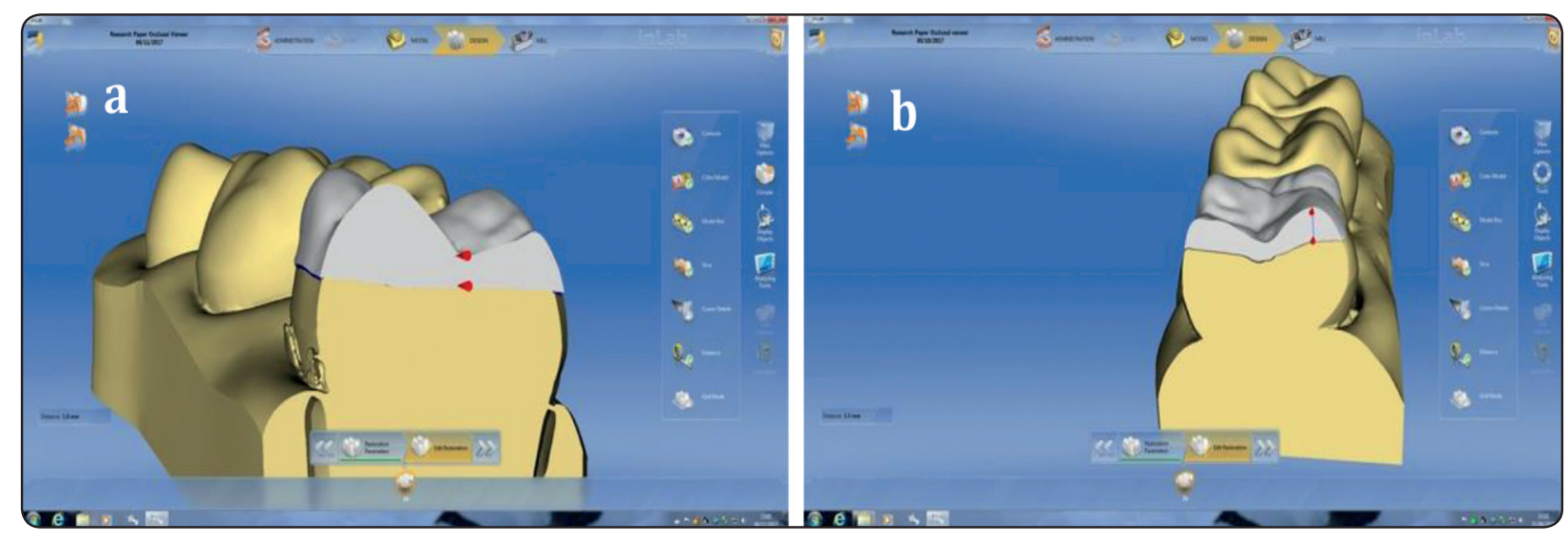

Fig. (8) Arrows pointing at sliced thickness of central groove of restoration adjusted as verified by software analysis tool at $1 \mathrm{~mm}$ (a), and at sliced thickness of cusp height adjusted at $1.5 \mathrm{~mm}$ (b).

After adjusting all the preparation parameters of the two tested occlusal veneer designs, the selected Celtra Duo and the Lava Ultimate blocks were then ready to start the milling process. The block was secured in place in the milling machine (Sirona MCXL Premium milling unit, Sirona Dental GmbH, Bensheim, Germany). After closing the milling machine door, the start button was clicked to begin the milling process (Fig 9). This process was performed ten times for each group to produce ten conventional occlusal veneers (five Celtra and five Lava veneers), and ten modified occlusal veneers of the two tested materials, five per each. After milling was completed, the ceramic block was loosened from the spindle with the setscrew, the veneer was removed and the sprue was cut using a diamond wheel.

The ten ceramic veneers of each group were tried for their initial seating and fitting on the original preparations in typodont and on their stone models using a magnifying lens and good lighting condition before crystallization/glaze firing of Celtra Duo veneers and finishing and polishing of Lava ultimate veneers following the manufacturer's instructions. The Celtra Duo occlusal veneers were fired at the recommended firing parameters for the crystallization/glazing program in Programat P510 furnace (Ivoclar-Vivadent, Schaan, Liechtenstein).
While, the Lava Ultimate veneers were finished and polished using the special kit supplied by the manufacturer. It started by the coarse then the medium rubber wheel, followed by the soft bristle brush spinned in Shofu Direct Dia paste followed by the Muslin Rag wheel in a gradual sequential steps with a low speed handpiece working slowly on the surface till obtaining a high luster. Assessment of the final fit and accuracy of the twenty occlusal veneers was then carried out by seating each veneer on each particular preparation on the stone model and on the master preparation on the typodont using the magnifying lens.

Duplication of the stone casts into epoxy resin (Chemapoxy resin, CMB chemicals, Egypt) was then carried out to obtain twenty epoxy resin casts (Fig 10). The occlusal veneer restorations were then checked on their particular epoxy models in order to make sure of their accuracy of fit before being adhesively bonded. The adhesive bonding of the two types of tested ceramics (Celtra Duo and Lava Ultimate) was undertaken following the instruction manual of each one. The only difference was that treatment of the intaglio surface of the Celtra veneers was done using hydrofluoric acid (IPS ceramic etching gel; Ivoclar-Vivadent, Schaan, Liechtenstein) for twenty seconds, rinsed under running water, 
then dried with oil free air for thirty seconds, while the intaglio surface of the Lava Ultimate veneers were sandblasted with aluminum oxide $(\leq 50 \mu \mathrm{m})$ at two bars (30 psi), then cleaned with alcohol and dried with oil free air. The intaglio surface of the twenty veneers were then silanated (Monobond S; Ivoclar-Vivadent) and allowed to dry for one minute. All the occlusal veneers were then bonded to their corresponding epoxy dies using self-adhesive dual cure resin cement (Rely X Unicem, 3M ESPE, St. Paul, Minnesota) following the manufacturer's instructions, while being seated under constant load of $2 \mathrm{Kg}$ for 30 seconds using a customized cementing device. ${ }^{37}$ Excess luting material was then removed and light polymerization was done on each surface for 40 seconds (Elipar LED curing unit, 3M ESPE). The adhesively bonded samples were then exposed to thermocycling program consisted of 2000 thermal cycles $\left(5^{\circ} \mathrm{C}\right.$ and $55^{\circ} \mathrm{C}$ in water) with a dwell time of 25 seconds in a computer controlled thermocycler (Robota automated thermal cycle; BILGE, Turkey). The twenty occlusal veneers were then subjected to the fracture resistance test, where each one was individually mounted on a computer controlled materials testing machine (Model 3345; Instron Industrial products, Norwwod, MA, USA) with a load cell of $5 \mathrm{KN}$ and data were recorded using computer software (Instron ${ }^{(R)}$ Bluehill Lite Software). The samples were secured to the lower fixed compartment of testing machine by tightening screws. Fracture test was done by compressive mode of load applied occlusally using a metallic rod with spherical tip (5.6 $\mathrm{mm}$ diameter) that simulates an opposing cusp positioned to achieve tripodization of contacts along the cusp inclines over the occlusal fossa. The spherical tip was attached to the upper movable compartment of testing machine travelling at cross head speed of $1 \mathrm{~mm} / \mathrm{min}$. A tin foil sheet was put in-between the spherical tip and the veneer to achieve homogenous stress distribution and minimize the transmission of local force peaks (Fig 11). The load at failure was manifested by an audible crack and confirmed by a sharp drop at load-deflection curve recorded using computer software. The load required to fracture was recorded in Newton. All the recorded data were collected and tabulated to be statistically analyzed. All the fractured specimens were inspected visually and under magnification to characterize the mode of failure of each specimen to be categorized according to the extent of the propagated cracks and fractures.

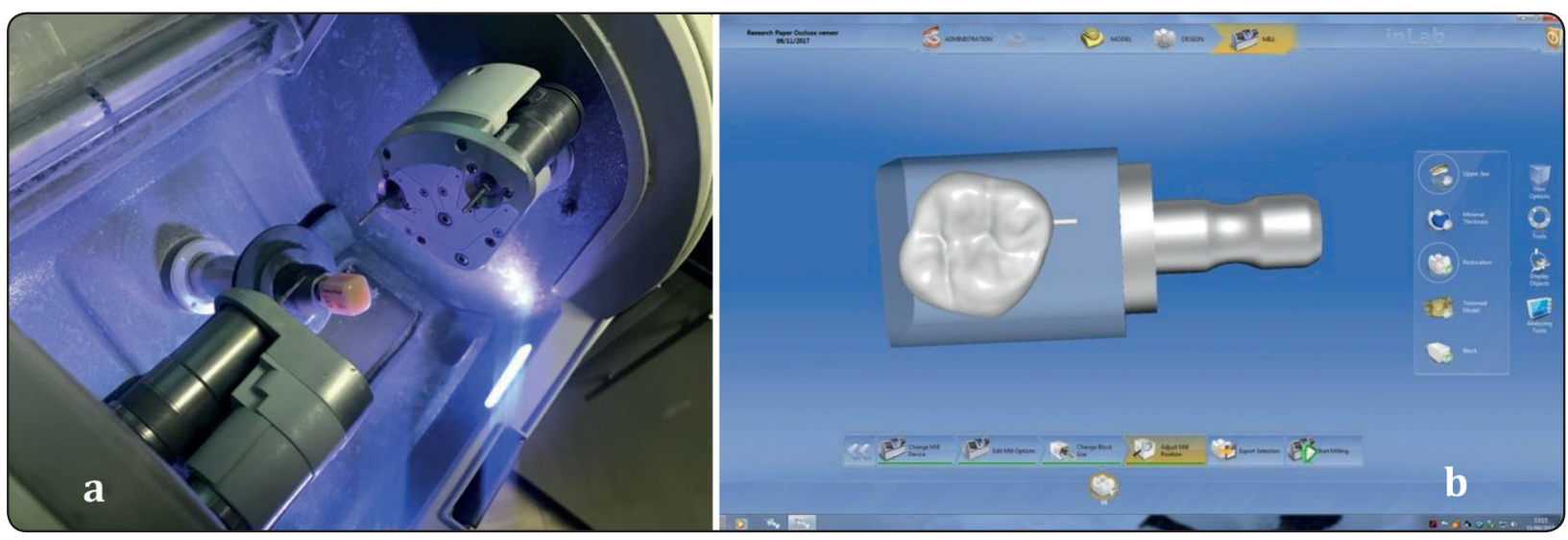

Fig. (9) The Celtra ceramic block secured in place in the milling machine (a). Virtual occlusal veneer design embedded in the block ready to start the milling process $(b)$. 


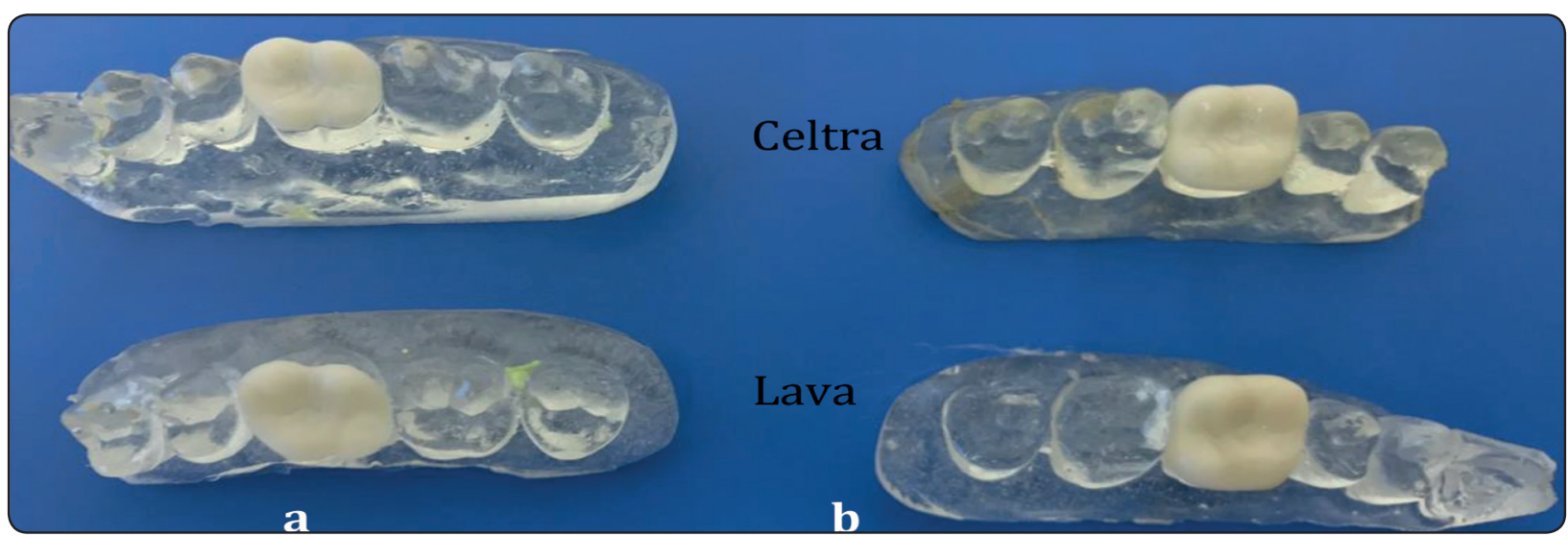

Fig 10: Epoxy resin casts with conventional occlusal veneer (a), and modified occlusal veneer (b), seated on their corresponding maxillary first molars.

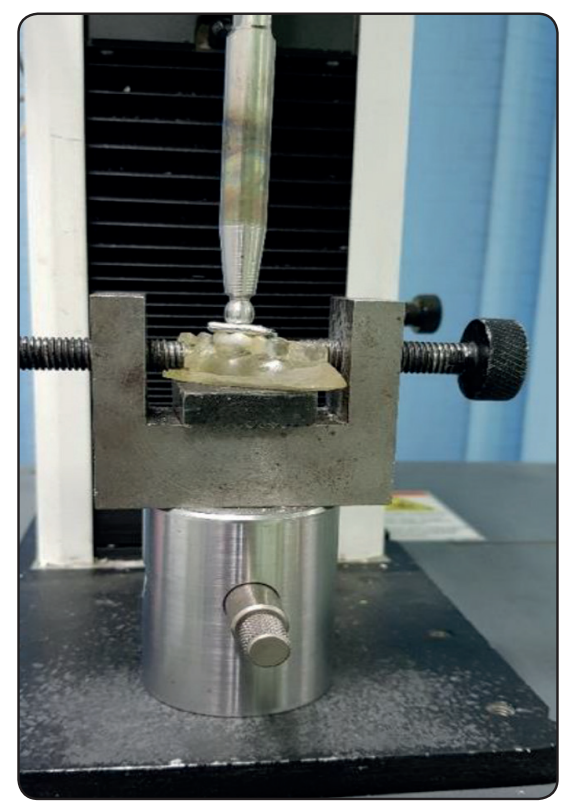

Fig. (11) The bonded occlusal veneer on its corresponding epoxy model while being subjected to fracture resistance test on the instron testing machine.

\section{RESULTS}

\section{Statistical analysis}

The mean and standard deviation values were calculated. Numerical data were explored for normality (Kolmogorov-Smirnov and Shapiro-Wilk tests). Data showed normal (parametric) distribution and were presented as mean, standard deviation (SD) and 95\% Confidence Interval (95\% CI) for the mean values. Two-way Analysis of Variance (ANOVA) was used to study the effect of design, ceramic type and their interaction on the mean fracture resistance. Bonferroni's post-hoc test was used for pairwise comparisons when ANOVA test proved significant. The significance level was set at $\mathrm{P} \leq 0.05$. Statistical analysis was performed with IBM (IBM Corporation, NY, USA), SPSS (SPSS, Inc; an IBM company) statistics version 20 for windows.

Descriptive statistics of fracture resistance $(\mathrm{N})$ of the two different occlusal veneer designs with the two different tested ceramic materials are presented in (Table 2).

TABLE (2): Descriptive statistics of fracture resistance mean values $(\mathrm{N})$ of the two designs and the two tested ceramics:

\begin{tabular}{|c|l|c|c|c|c|}
\hline \multirow{2}{*}{$\begin{array}{c}\text { Ceramic } \\
\text { type }\end{array}$} & Design & Mean & SD & \multicolumn{2}{|c|}{$95 \%$ CI } \\
\cline { 5 - 6 } & & & & $\begin{array}{c}\text { Lower } \\
\text { bound }\end{array}$ & $\begin{array}{c}\text { Upper } \\
\text { bound }\end{array}$ \\
\hline \multirow{2}{*}{ Celtra } & Conventional & 1016.9 & 91.8 & 902.9 & 1130.9 \\
& Modified & 882.2 & 53.6 & 815.7 & 948.7 \\
\hline \multirow{2}{*}{ Lava } & Conventional & 898.3 & 109.7 & 762.2 & 1034.5 \\
& Modified & 1329.9 & 96.1 & 1210.6 & 1449.3 \\
\hline
\end{tabular}

Two-way ANOVA results: (Table 3).

The results showed that the occlusal veneer design and the ceramic type and the interaction between these variables had a statistically significant effect on mean fracture resistance. Since the interaction between the variables is statistically significant, so the variables are dependent upon each other. 
TABLE (3): Two-way ANOVA results for the effect of different variables on mean fracture resistance:

\begin{tabular}{|c|c|c|c|c|c|c|}
\hline Source of variation & $\begin{array}{c}\text { Type III Sum of } \\
\text { Squares }\end{array}$ & $\mathrm{df}$ & Mean Square & F-value & $P$-value & $\begin{array}{c}\text { Partial Eta Squared } \\
\text { (Effect size) }\end{array}$ \\
\hline Ceramic type & 135482.3 & 1 & 135482.3 & 16.6 & $0.001^{*}$ & 0.510 \\
\hline Design & 110169.2 & 1 & 110169.2 & 13.5 & $0.002^{*}$ & 0.458 \\
\hline Ceramic type x Design interaction & 400875.3 & 1 & 400875.3 & 49.2 & $<0.001^{*}$ & 0.755 \\
\hline
\end{tabular}

$d f:$ degrees of freedom $=(n-1) *:$ Significant at $P \leq 0.05$

\section{Effect of design regardless of ceramic type (Table}

\section{4, Fig 12):}

Regardless of ceramic type, conventional design showed statistically significant lower mean fracture resistance than modified design.

TABLE (4): The mean, standard deviation (SD) values $(\mathrm{N})$ and results of two-way ANOVA test for comparison between fracture resistance of the two designs regardless of ceramic type.

\begin{tabular}{|c|c|c|c|c|}
\hline \multicolumn{2}{|c|}{ Conventional } & \multicolumn{2}{c|}{ Modified } & \multirow{2}{*}{ P-value } \\
\cline { 1 - 4 } Mean & SD & Mean & SD & \\
\hline 957.6 & 114.0 & 1106.0 & 247.1 & $0.002 *$ \\
\hline
\end{tabular}

*: Significant at $P \leq 0.05$

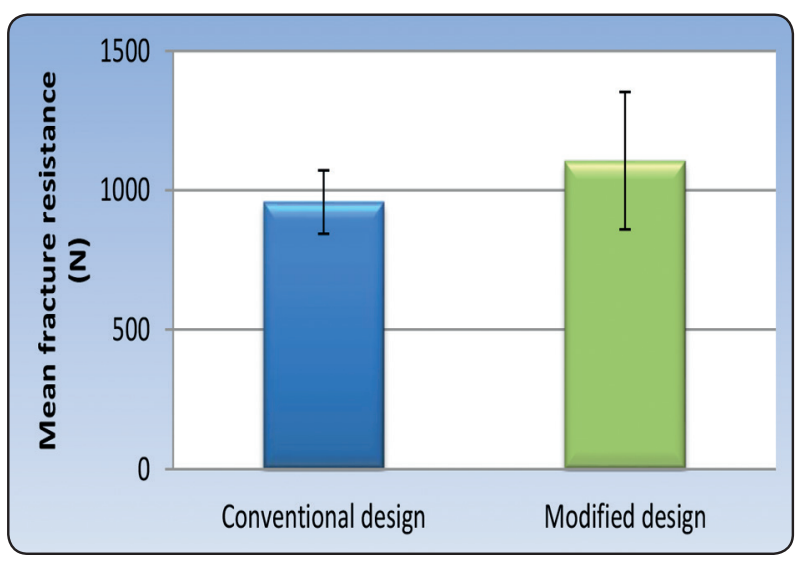

Fig 12: Bar chart representing mean and standard deviation values for fracture resistance of the two designs regardless of ceramic type.

\section{Effect of Ceramic type regardless of design (Table 5, Fig 13):}

Regardless of design, Celtra Duo (ZLS ceramic) showed statistically significant lower mean fracture resistance than Lava Ultimate (hybrid ceramic).

TABLE (5): The mean, standard deviation (SD) values $(\mathrm{N})$ and results of two-way ANOVA test for comparison between fracture resistance of the two ceramic types regardless of the design.

\begin{tabular}{|c|c|c|c|c|}
\hline \multicolumn{2}{|c|}{ Celtra } & \multicolumn{2}{c|}{ Lava } & \multirow{2}{*}{$P$-value } \\
\cline { 1 - 3 } Mean & SD & Mean & SD & \\
\hline 949.5 & 100.3 & 1114.1 & 247.4 & $0.001^{*}$ \\
\hline
\end{tabular}

*: Significant at $P \leq 0.05$

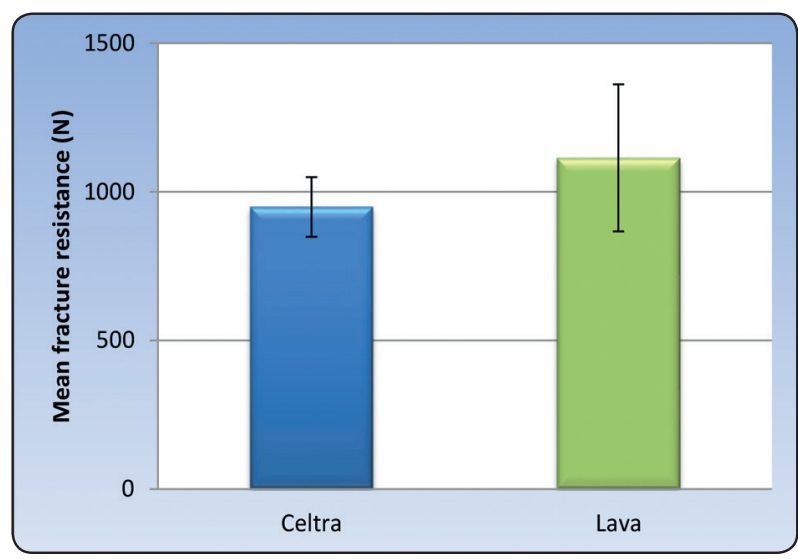

Fig. (13) Bar chart representing mean and standard deviation values for fracture resistance of the two ceramic types regardless of the design. 


\section{Effect of different interactions (Table 6, Fig 14):}

\section{a) Comparison between the two ceramic types}

With conventional design; there was no statistically significant difference between the two ceramic types. With the modified design; Celtra Duo showed statistically significant lower mean fracture resistance than Lava Ultimate.

\section{b) Comparison between the two designs}

With Celtra Duo; conventional design showed statistically significant higher mean fracture resistance than modified design. With Lava Ultimate; conventional design showed statistically significant lower mean fracture resistance than modified design.

\section{Failure Mode Analysis}

After the samples were subjected to fracture resistance test, they were examined using a magnifying lens under strong lighting condition and photographed at high magnification to detect and characterize the different failure modes. Thorough examination of the twenty samples revealed that the failure findings ranged between small occlusal hair line cracks following mostly a mesio-distal pattern representing the major number of samples (55\%), followed by the large occlusal cracks involving only the ceramic material (45\%), and the least was a catastrophic failure that was represented by one sample only $(5 \%)$, which involved the veneer and the epoxy die. Therefore, it was decided to classify these failure patterns into three types (Table 7), type I, II, and III, and figure $15(\mathrm{a}, \mathrm{b}, \mathrm{c})$.

TABLE (6): The mean, standard deviation (SD) values (N) and results of two-way ANOVA test for comparison between fracture resistance of the different interactions.

\begin{tabular}{|c|c|c|c|c|c|}
\hline \multirow{2}{*}{ Design } & \multicolumn{2}{|c|}{ Celtra } & \multicolumn{2}{c|}{ Lava } & \multirow{2}{*}{$\begin{array}{c}\text { P-value } \\
\text { (Between } \\
\text { Ceramic types) }\end{array}$} \\
\cline { 2 - 5 } & Mean & SD & Mean & SD & 0.054 \\
\hline Conventional & 1016.9 & 91.8 & 898.3 & 109.7 & $<0.001 *$ \\
\hline Modified & 882.2 & 53.6 & 1329.9 & 96.1 & \\
\hline$P$-value (Between designs) & \multicolumn{3}{|c|}{$0.031 *$} & \multicolumn{2}{c|}{$<0.001 *$} \\
\hline
\end{tabular}

*: Significant at $P \leq 0.05$

TABLE (7): Distribution of the failed samples according to the three types as detected with the two tested designs and ceramic materials.

\begin{tabular}{|c|c|c|c|c|c|c|}
\hline Ceramic Material & \multicolumn{2}{|c|}{ Celtra } & \multicolumn{2}{c|}{ Lava } & \\
\hline Design & $\begin{array}{c}\text { Conventional } \\
\text { Design }\end{array}$ & Modified Design & $\begin{array}{c}\text { Conventional } \\
\text { Design }\end{array}$ & Modified Design & Total \\
\hline Type I Failure & 3 & 2 & 4 & 2 & 11 & 55 \\
\hline Type II Failure & 2 & 3 & - & 3 & 8 & 45 \\
\hline Type III Failure & - & - & 5 & 5 & 20 & 100 \\
\hline Total & 5 & 5 & 5 & & & 5 \\
\hline
\end{tabular}




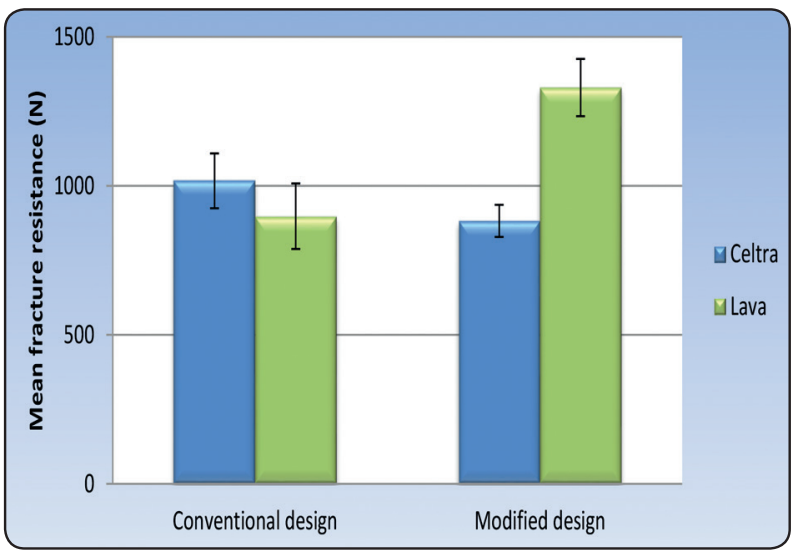

Fig. (14) Bar chart representing mean and standard deviation values for fracture resistance of the different interactions.

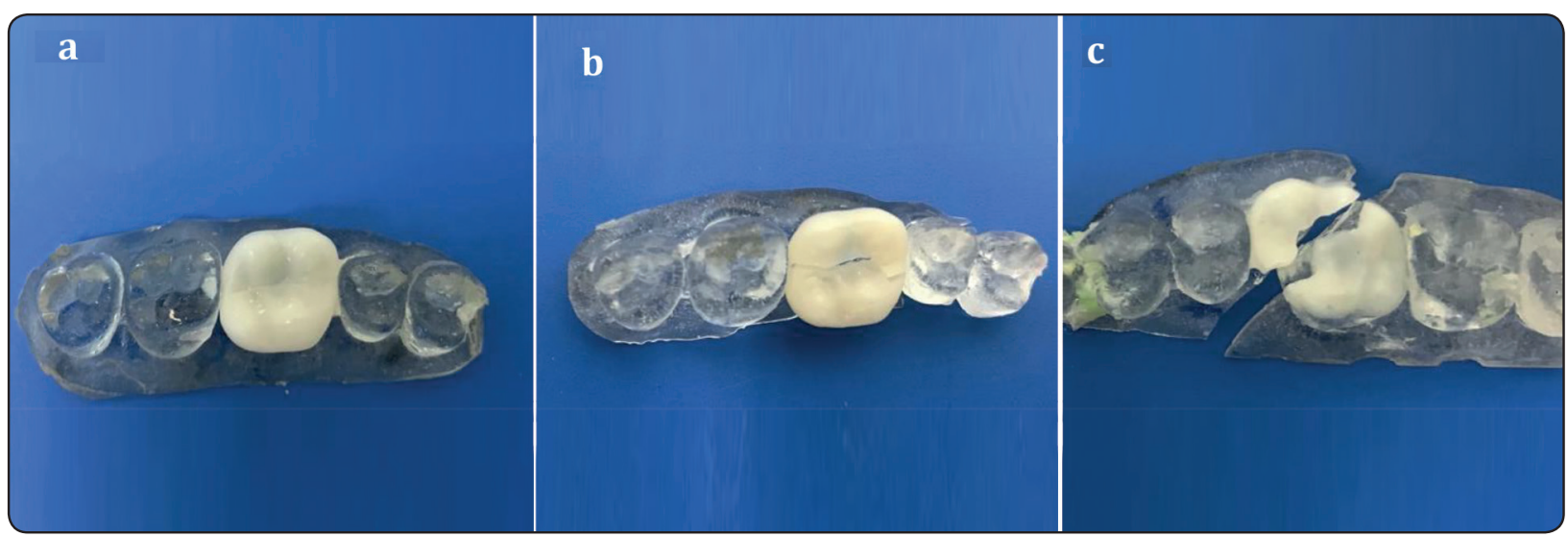

Fig. (15) (a,b,c): Showing the three detected failure patterns where Type I represents the mild failure pattern (a), and Type II represents the moderate failure pattern (b), and Type III showing a catastrophic failure (c).

\section{DISCUSSION}

The null hypothesis of the present investigation, namely, that there would be no difference in fracture resistance between the two designs or ceramic materials tested, was rejected according to the statistical analysis of the obtained data, which revealed that there was a significant difference in fracture resistance of the two tested occlusal veneer designs, as well as, of the two tested ceramic materials.

Pathologic loss of coronal tooth structure or severe tooth wear like abrasion and erosion is not uncommon in the general population as reported by Abrahamsen, ${ }^{2}$ and Spijker et al. ${ }^{38}$ Its diagnosis in the early stages is challenging even for trained clinicians (Bartlett). ${ }^{39}$ Therefore, the importance of re-establishment of optimum functional equilibrium parameters had been the area of interest and concern for many researchers. ${ }^{1,6,8,15}$

Recent developments of restorative materials, technology of construction techniques, and advanced adhesive approaches have encouraged the fixed prosthodontists towards more conservative plans of treatment. ${ }^{7-9,40}$

Occlusal veneers are considered the latest therapeutic approach to solve the problem of advanced erosive lesions conservatively. ${ }^{7,41,42}$ However, Schlichting et al, ${ }^{8}$ reported that the best restorative material is yet to be known. They considered that only bonded ceramics and composite resins address the biomimetic principles of conservation and esthetics. 
Therefore, the main interest of the present in vitro investigation was directed specifically toward proposing a new occlusal veneer design that can make the best mechanical advantage with the newly introduced zirconia lithium silicate ceramic and a nano-hybrid ceramic as far as fracture resistance and failure mode are concerned.

For the purpose of standardization in this research, preparations of the proposed occlusal veneer design and the conventional design were carried out on two maxillary first molars of a typodont, and twenty elastomeric impressions were made, ten per each group using sectional trays to record the quarter side of each prepared molar. The impressions were then poured using Type IV dental stone to produce twenty stone models including the prepared tooth with two neighboring teeth mesially and distally to it, in order to simulate the actual clinical situation while recording the proximal contacts and occlusal configurations.

In order to guarantee optimum standardization of the construction technique for all the veneers concerning the thickness, anatomical features, and internal fit, together with avoiding many technical laboratory variables, CAD/CAM technology was chosen. ${ }^{43}$

The occlusal veneers were checked for accuracy on the stone casts before being checked on their corresponding epoxy resin casts, upon which adhesive bonding was carried out following the standard recommended protocol for each ceramic type.

In order to simulate the clinical conditions to which the restorations will be subjected, thermal cycling was carried out; 2000 cycle program from $5^{\circ} \mathrm{C}$ to $55^{\circ} \mathrm{C}$, which represents one year clinical service, was chosen according to previous studies. ${ }^{44-47}$

Fracture resistance was considered to be the most important and determining factor for the clinical longevity of all-ceramic restorations. ${ }^{48}$ Yucel et al, ${ }^{49}$ reported that the fracture resistance of all-ceramic restorations depends on modulus of elasticity of the chosen abutment material. Wood et al, ${ }^{50}$ and Zahran et al, ${ }^{51}$ suggested epoxy resin to be used as a die material for this purpose as it reacts elastically as natural dentin does, therefore, it was chosen in the present investigation.

Waltimo and Kononen, ${ }^{52}$ using a novel bite force recorder found that the biting forces in the molar region ranged between $597 \mathrm{~N}$ to $847 \mathrm{~N}$ for young women and men respectively. Gibbs et al, ${ }^{53}$ Lundgren and Laurell, ${ }^{54}$ reported that normal masticatory forces ranged between $37 \%$ to $40 \%$ of the biting force.

In the present research, the mean fracture loads for the two occlusal veneer designs and the two ceramic materials were beyond the range of realistic occlusal forces in the posterior region (Table 2). Therefore, it can be assumed that all the tested specimens can withstand the maximum intraoral posterior masticatory forces.

Regarding the effect of the occlusal veneer designs, the modified design showed higher mean statistically significant fracture resistance value $(1106.0 \pm 247.1)$ than the conventional design $(957.6 \pm 114.0)$ (Table 4) and (Fig 12). This might be attributed to the advantage given to this design by the circumferential finish line which equally distributed the stresses over the tooth, in addition to the relative bulk added proximally to the veneers through the two slots at this critical contact area. In spite of the lower fracture resistance mean value obtained with the conventional planar occlusal veneer design, it also revealed favorable mode of failure. The modes of failure of the two designs ranged mostly between Types I and II (Table 7) which constitutes $55 \%$ and $45 \%$ respectively. These failure modes which lied between cracks or fractures of the veneer material only without involving the epoxy die (Fig 15 a and b) are in accordance with the findings of Magne et al, ${ }^{10}$ Johnson et al, ${ }^{26}$ and Schlichting et al, ${ }^{32}$ who considered failures that are limited to the restorative material improve the longevity prognosis of the restored teeth, since, the occlusal veneer can be easily replaced by 
milling an identical one. However, one sample only of the conventional design was recorded as Type III in which catastrophic failure was detected through splitting of the veneer and the epoxy die (Fig 15c).

Concerning the fracture resistance of the two tested occlusal veneer materials; the zirconia lithium silicate "Celtra Duo" and the nano-hybrid ceramic (Lava Ultimate), the statistical analysis of the obtained data (Table 5 and Fig 13) revealed that the Lava Ultimate mean values were higher significantly than those of Celtra Duo. These findings are in line with those of Schlichting et al, ${ }^{8} \mathrm{Johnson}$ et al, ${ }^{26}$ Magne et al, ${ }^{42}$ and Egbert et al, ${ }^{55}$ who found that occlusal veneers made with the resin nano-ceramic composite material (Lava Ultimate) or similar hybrid ceramics offered the highest fracture strength under vertical loading than the other tested ceramic materials. The Lava Ultimate blocks; according to the manufacturer, ${ }^{31}$ contain nanodisperse, non-aggregated, non agglomerated nanoparticles of silica (20 nm diameter) and zirconia (4-11 nm diameter) forming nano-clusters (0.6$10 \mu \mathrm{m})$ that give structural integrity and allow a high proportion of ceramic fillers to be incorporated. Also, the interstitial spaces between the particles are filled with more nanomers leading to high ceramic content as reported by the manufacturer (3M ESPE).

The review of literature is deficient in investigations concerning the recently introduced zirconia reinforced lithium silicate (ZLS) ceramic, particularly as occlusal veneer restorations. Most of the studies evaluated and compared the mechanical properties of ZLS with lithium disilicate, ${ }^{56}$ or with polymer infiltrated ceramic network (PICN) (Vita Enamic) and (IPS e.max CAD) in a crown design. ${ }^{33}$ They reported that masticatory fatigue mostly did not affect the fracture strength of crowns, regardless of the material and thickness. They concluded that PICN and ZLS ceramic could be an alternative to lithium disilicate ceramic regarding its fracture strength.

On the other hand, Al-Akhali et al, ${ }^{57}$ evaluated the influence of thermodynamic loading on the du- rability and fracture resistance of four dental CAD/ CAM occlusal veneers: lithium disilicate (e.max CAD), ZLS (Vita Suprinity)), Polymer-infiltrated ceramic (Vita Enamic), and PMMA (Telio CAD). They reported that ZLS (Vita Suprinity) veneers showed significantly higher fracture resistance than occlusal veneers made from resin containing materials (Vita Enamic and Telio CAD). The lithium disilicate (e.max CAD) showed significantly higher fracture resistance than PMMA (Telio CAD) restorations. This might not be in accordance with the present results which could be explained by the difference in the tested materials, where Lava Ultimate proved to have superior mechanical performance than Vita Enamic (Egbert et al). ${ }^{55}$

Statistical analysis of the different interactions of the variables in the present study (Table 6 and Fig 14) revealed that the Lava Ultimate occlusal veneers presented the highest fracture resistance with the modified design $(1329.9 \pm 96.1 \mathrm{~N})$, followed by Celtra Duo veneers with the conventional design $(1016.9 \pm 91.8 \mathrm{~N})$. The least fracture resistance values were recorded for Lava Ultimate veneers with the conventional design $(898.3 \pm 109.7 \mathrm{~N})$ and Celtra Duo veneers with the modified design $(882.2 \pm 53.6 \mathrm{~N})$

In spite that all these fracture resistance values exceed the range of clinical acceptability, ${ }^{34,52,58}$ it can be recommended that in cases with increased occlusal forces, Lava Ultimate occlusal veneer with the modified design be the first choice, followed by "ZLS" Celtra Duo with the conventional design as a second choice, under the circumstances of the present research.

However, putting in mind the limitations in the present study, it threw some light toward a creative thinking concerning this new era of ceramic technology with huge varieties of materials and suggesting preparation designs that suit the properties of such materials, aiming to fulfil the optimum conservative approach. 
It is recommended that new investigations be undertaken using new different ceramic materials including the nano-hybrid ceramics with different occlusal veneer designs on natural teeth to be tested in an artificial chewing simulator. Following that, assessment of the clinical performance of these occlusal veneers would be the best judgment for their serviceability and longevity.

\section{CONCLUSIONS}

Based on the findings of this research and under its limitations, the following conclusions were made:

1. The modified occlusal veneer design offered promising results as far as fracture resistance is concerned particularly with the nano-hybrid ceramic (Lava Ultimate), which presented the highest statistically significant fracture resistance mean values.

2. The conventional planar occlusal veneer design proved to be superior with ZLS (Celtra Duo) as it presented highly significant fracture resistance mean values compared to the modified design.

3. Both the conventional and modified occlusal veneer designs presented fracture resistance mean values with the two tested materials "Celtra Duo and Lava Ultimate" that exceeded the range of clinical acceptability.

4. Rating of the tested occlusal veneers according to their fracture resistance mean values is as follows: the highest for the Lava Ultimate with the modified design followed by Celtra Duo with the conventional design, then Lava Ultimate with conventional design and Celtra Duo with modified design.

5. It can be recommended that in cases with increased occlusal stresses, Lava Ultimate occlusal veneer with the modified design be the first choice followed by the Celtra Duo with the conventional design as a second choice.
6. All the fractured occlusal veneers revealed favorable failure mode except one, where the cracks were within the veneers only, which indicates their reparability through milling new alternatives instead.

\section{REFERENCES}

1. Magne P, Belser U. Bonded porcelain restorations in the anterior dentition: a biometric approach. Chicago: Quintessence; 2002. 23-55.

2. Abrahamsen TG. The worn dentition-pathognomonic patterns of abrasion and erosion. Int Dent J 2005: 55: 268-76.

3. Lussi A. Hellwia E. Ganss C. Jaeggi T. Bunocore Memorial Lecture. Dental Erosion. Oper Dent 2009; 34: 245-62

4. Turner KA, Missirlian DM. Restoration of the extremely worn dentition. J Prosthet Dent 1984; 52: 467-74.

5. Al-Omiri MK, Lamey PJ, Clifford T. Impact of tooth wear on daily living. Int J Prosthodont 2006; 19: 601-5.

6. Moslehifard E, Nikzad S, Geraminpanah F, et al. Fullmouth rehabilitation of a patient with severely worn dentition and uneven occlusal plane: a clinica report. J Prosthodont 2012; 21: 56-64

7. Edelhoff D, Sorensen JA. Tooth structure removal associated with various preparation designs for posterior teeth. Int J Periodontics Restorative Dent 2002; 22: 241-9.

8. Schlichting LH, Maia HP, Baratieri LN, Magne P. Noveldesign ultra-thin $\mathrm{CAD} / \mathrm{CAM}$ composite resin and ceramic occlusal veneers for the treatment of severe dental erosion. J Prosthet Dent 2011; 217-26.

9. Cortellini D, Canale A. Bonding lithium di-silicate ceramic to feather-edge tooth preparations: A minimally invasive treatment concept. J Adhes Dent 2012, 14: 7-10.

10. Magne P, Stanley K, Schlichting LH. Modeling of ultrathin occlusal veneers. Dent Mater. 2012; 28 (7): 777-782.

11. Tinschert J, Natt G, Mautsch W, Augthun M, Spiekermann P. Fracture resistance of lithium disilicate-, alumina-, and zirconia based three-unit fixed partial dentures: a laboratory study. Int J Prosthodont 2001; 14:231-8.

12. Leinfelder KF. Indirect posterior composite resins. Compend Contin Educ Dent 2005; 26: 495-503.

13. Spreafico RC, Krejci I, Dietschi D. Clinical performance and marginal adaptation of Class II direct and semi direct 
composite restorations over 3.5 years in vivo. J Dent 2005; 33: 499-507.

14. Beuer F, Schweiger J, Edelhoff D. Digital dentistry: an overview of recent developments for $\mathrm{CAD} / \mathrm{CAM}$ generated restorations. Br Dent J 2008: 204: 505-11.

15. Schlichting LH, Resende T H, Reis K R, and Magne P. Simplified treatment of severe dental erosion with ultrathin CAD/CAM composite occlusal veneers and anterior bilaminar veneers. J Prosthet Dent 2016; 116: 474-482.

16. Magne P. Immediate dentin sealing: a fundamental procedure for indirect bonded restortions. J Esthet Restor Dent 2005; 17: 144-54.

17. Magne P, SO WS, Cascione D. Immediate dentin sealing supports delayed restoration placement. J Prosthet Dent 2007; 98: 166-74.

18. Spohr AM, Borges GA, Platt JA. Thichness of immediate dentin sealing materials and its effect on the fracture load of a reinforced all-ceramic crown. Eur J Dent 2013; 7: 474-483.

19. Chiggi PC, Steiger AK, Mareondes MI, Mota EG, Junior BLH, Spohr AM. Does immediate dentin sealing influence the polymerization of impression materials? Eur J Dent; 8: 366-372.

20. Pashley DH, Tay FR, Breschi L, Tjaderhane L, Carvalho RM, Carilho M, Tevergil-Mutluay. A state of the art etchand-rinse adhesives. Dent Mater 2011; 27: 1-16.

21. Federlin M, Sipos C, Hiller KA, Thonemann B, Schmatz G. Partial ceramic crowns. Influence of preparation design and luting material on marginal integrity - a scanning electron microscopic study. Clin Oral Invest 2005; 9: 8-17.

22. Manhart J, Chen H, Hamm G, Hickel R. Buonocore Memorial Lecture. Review of the clinical survival of direct and indirect restorations in posterior teeth of the permanent dentition. Oper Dent 2004; 29: 481-508.

23. Burke FJ. Maximising the fracture resistance of dentinebonded all ceramic crowns. J Dent 1999; 27: 169-73.

24. Bindl A, Mormann WH. Survival rate of mono-ceramic and ceramic-core $\mathrm{CAD} / \mathrm{CAM}$ - generated anterior crowns over 2-5 years. Eur J Oral Sci 2004; 112: 197-204.

25. Tsitrou EA, Helvatjoglu - Antoniades M, van Noort R. A preliminary evaluation of the structural integrity and fracture mode of minimally prepared resin bonded CAD/CAM crown. J Dent 2010; 38: 16-22.
26. Johnson AC, Versluis A, Tantbirojn D, Ahuja S. Fracture strength of CAD/CAM composite and composite-ceramic occlusal veneers. J Prosthodont Res 2014; 58: 107-114.

27. Denry I, and Kelly JR. "Emerging ceramic-based materials for dentistry.” J Dent Res 2014; 93:1235-1242.

28. Traini T, Sinjari B, Pascetta R, Serafini N. The zirconia reinforced lithium silicate ceramic: lights and shadows of a new material. Dent Mater J 2016; 35: 748-755.

29. Gracis, S, Thompson VP, Ferencz JL, Silva, Nelson RFA; Bonfante, Estevam A. A new classification system for all-ceramic and ceramic like restorative materials. Int $\mathrm{J}$ Prosthodont 2015; 28: 227-235.

30. Presi V, Behr M, Hahnel S, Rosentritt M. Influence of cementation on in vitro performance, marginal adaptation and fracture resistance of CAD/CAM- fabricated ZLS molar crowns. Dent Mater 2015; 31: 1363-1369.

31. 3M ESPE, Lava ${ }^{\mathrm{TM}}$ Ultimate CAD/CAM Restorative Technical Product Profile, Last accessed 30 Oct 2014.

32. Schlichting LH, Maia HP, Baratieri LN, Magne P. Novel design ultra-thin $\mathrm{CAD} / \mathrm{CAM}$ composite resin and ceramic occlusal veneers for the treatment of severe dental erosion. J Prosthet Dent 2011; 105: 217-26.

33. Sieper K, Wille AM, Kern M. Fracture resistance of lithium disilicate crowns compared to polymer-infiltrated ceramic-network and zirconia reinforced lithium silicate crowns. J Mech Behav Biomed Mater 2017; 74: 342-348.

34. Magne P, Knezevic A. Simulated fatigue resistance of composite resin versus porcelain CAD/CAM overlay restorations on endodontically treated molars. Quintessence Int 2009; 40: 125-33.

35. Guess P, Schulthesis S, Wolk M, Zhang Y, Strub J. Influence of prepsrstion design and ceramic thicknesses on fracture resistance and failure modes of premolar partial coverage restorations. J Prosthet Dent 2013; 110: 264-73.

36. Nakamura T, Tanaka H, Yatani H: In vitro study on marginal and internal fit of CAD/CAM all-ceramic crowns. Dent Mater J 2005; 24: 456-9.

37. Carl Hany and Maha Taymour. Fracture Resistance and Failure Mode of Two Restoration Designs Made of Monolithic Hybrid and Glass Machinable Ceramics: In vitro study. E.D.J 2017; 63: 1009-1021.

38. Van't Spijker A, Rodriguez JM, Kreulen CM, et al. Prevalence of tooth wear in adults. Int J Prosthodont 2009; 22: 35-42. 
39. Bartlett DW. The role of erosion in tooth wear: etiology, prevention, and management. Int D J 2005; 55: 277-84.

40. Burke FJ, Kelleher MG, Wilson N, et al. Introducing the concept of pragmatic esthetics, with special reference to the treatment of tooth wear. J Esthet Restor Dent 2011; 23: 277-93.

41. Magne P. Composite resins and bonded porcelain: The Postamalgam era? J Calif Dent Assoc 2006; 34: 135-47.

42. Magne P, Schlichting LH, Maia HP, Baratieri LN. In vitro fatigue resistance of CAD/CAM composite resin and ceramic posterior occlusal veneers: J Prosthet Dent 2010, 104: 149-57.

43. Beuer F, Schweiger J, Edelhoff D. Digital dentistry: an overview of recent developments for $\mathrm{CAD} / \mathrm{CAM}$ generated restorations. Br Dent J 2008; 204: 505-11.

44. Galea M and Darvelb B. Thermal cycling procedures for laboratory testing of dental restorations: J Dent 1999; 27: 89-99.

45. Yang R, Arola D, Han Z and Zhang X. A comparison of the fracture resistance of three machinable ceramics after thermal and mechanical fatigue: J Prosthet Dent 2014; 112: 878-885.

46. Vasquez VZ, Ozcan M, and Kimpara ET: Evaluation of interface characterization and adhesion of glass ceramics to commercially pure titanium and gold alloy after thermal and mechanical loading: Dent Mater 2009; 25: 221-31.

47. Vasquez VZ, Ozcan M, Nishioka R, Souza R, Mesquita A, and Pavanellic C: Mechanical and thermal cycling effects on the flexural strength of glass ceramics fused to titanium. Dent Mater J 2008; 27:7-15.

48. Pröbster L, and Diehl J: Slip-casting alumina ceramics for crown and bridge restorations. Quint Int 1992; 23: 25-31.

49. Yucel MT, Yondem I, Aykent F, Eraslan O: Influence of the supporting die structures on the fracture strength of all-ceramic materials. Clin Oral Investigations 2012; 16:1105-10.
50. Wood KC, Berzins DW, Luo Q, Thompson GA, Toth JM, and Nagy WW: Resistance to fracture of two all-ceramic crown materials following endodontic access. J Prosthet Dent 2006; 95: 33-41.

51. Zahran M, El-Mowafy O, Tam L, Watson PA and Finery. Fracture strength and fatigue resistance of all-ceramic molar crowns manufactured with CAD/CAM technology. J Prosthodont 2008; 17:370-77.

52. Waltimo A and Kononen M: A novel bite force recorder and maximal isometric bite force values for healthy young adults. Scand J Dent Res 1993; 101: 171-5.

53. Gibbs CH, Mohan PE, Lundeen HC, Brehnan K, Wals EK, and Holbrook WB: Occlusal forces during chewing and swallowing as measured by sound transmission. J Prosthet Dent 1981; 46:443-9.

54. Lundgren D, and Laurell L: Occlusal force pattern during chewing and biting in dentition restored with fixed bridges of cross-arch extension. I. Bilateral end abutments. J Oral Rehabil 1986; 13: 57-71.

55. Egbert JS, Johnson AC, Tantbirojn D, Versluis A. Fracture strength of ultrathin occlusal veneer restorations made from CAD/CAM composite or hybrid ceramic materials. Oral Sc Int 2015; 12: 53-58.

56. Elsaka SE, Elnaghy AM. Mechanical properties of zirconia reinforced lithium silicate glass ceramic. Dent Mater 2016; 32: 908-914.

57. Al-Akhali M, Chaar MS, Elsayed A, Samran A, Kern M. Fracture resistance of ceramic and polymer-based occlusal veneer restorations. J Mech Behav Biomed Mater 2017; 74: 245-250.

58. Magne P, Knezevic A. Influence of overlay restorative materials and load cusps on the fatigue resistance of endodontically treated molars. Quintessence Int 2009; 40: 729-37. 